\title{
Congenital hypothyroidism. Clinical and laboratory characteristics in infants detected by neonatal screening
}

\author{
DARRELL A PRICE, ROBERT M EHRLICH, AND PAUL G WALFISH
}

Department of Pediatrics, Endocrine Division, Hospital for Sick Children, Toronto, and Mount Sinai Hospital, Thyroid Research Laboratory and Endocrine Division, University of Toronto Medical School, Toronto, Ontario, Canada

SUMMARY The clinical and laboratory characteristics of infants with neonatal hypothyroidism, and the age at which treatment was started are reviewed. The incidence of primary hypothyroidism was 1 in 3488 live births. Most of these cases were detected in a cord blood screening programme which was carried out between October 1973 and May 1980 in the Toronto region. Forty-eight infants with primary persistent hypothyroidism were classified by technetium scintiscanning as follows: 12 with athyrosis (non-visualised thyroid glands), 14 with ectopic thyroid glands, and 14 with goitrous thyroid glands. The remaining 8 infants comprised 4 with hypoplasia and 4 with transient hypothyroidism ( 2 idiopathic and 2 iodide induced). Although infants with athyrosis had a lower mean thyroxine value, their values overall were not significantly different from those of the other groups. Some infants, particularly those who were goitrous or ectopic, initially had normal thyroxine values. Skeletal maturation was more often delayed in athyrotic infants than in the ectopic or goitrous group. Radioactive iodine uptakes were appreciably higher in the goitrous group, and there was no significant difference between athyrotic and ectopic groups. The mean age at which treatment was started for all patients was 25 (range 6-120) days. The average age for starting treatment using initial thyroxine and secondary thyrotrophin testing in the initial stages of the cord blood screening was 36 days. The use of initial cord serum or dried blood thyrotrophin reduced the start of treatment to 14 days. It is concluded that: (1) It is important to determine the precise anatomical diagnosis, the biochemical severity, and the age at which treatment is started in order to assess the benefits of regional screening programmes in the detection of neonatal hypothyroidism. (2) Routine technetium scintiscanning before the start of treatment helps to determine the diagnosis. (3) Radioactive ${ }^{131}-I$ thyroid uptake studies are no longer routinely recommended; this is because of the radiation hazard and the lack of specificity in differentiating between the various anatomical types. (4) The feasibility of cord blood screening to detect the various causes of neonatal hypothyroidism is confirmed. (5) The time between final diagnosis and the institution of treatment can be reduced by 2 or 3 weeks if a thyrotrophin test is used initially from cord blood serum or, preferably, from dried blood spotted on filter paper; the latter is easier to post to a screening laboratory.

Screening programmes for congenital hypothyroidism have been conducted in North America since the early 1970s. ${ }^{1}$ Preliminary results from Toronto, ${ }^{2-4}$ other centres in North America, ${ }^{5}$ Europe ${ }^{6-8}$ and from $\mathrm{Japan}^{9}{ }^{10}$ have been reported. The incidence of congenital hypothyroidism has been estimated to be between $1: 3000$ and 1:5000 live births. ${ }^{1-8}$ Before the advent of thyroid screening it was felt that the majority of cases of congenital hypothyroidism were due to athyrosis, ${ }^{11}{ }^{12}$ but it is now apparent that there are other causes of primary hypothyroidism. As it is not known whether the anatomical diagnosis, the biochemical severity, or the age at which treatment is started affect the prognosis, these facts were recorded in each patient. It was hoped that a conclusion might be drawn on the benefits of a regional screening programme. In previous reports on infants with congenital 
hypothyroidism detected by neonatal screening programmes, about half the patients were started on treatment without the underlying anatomical abnormality being defined.561314 However at our centre each infant had been given his anatomical diagnosis before treatment was started. This has enabled us to determine more precisely the incidence of such abnormalities, and to characterise the clinical and laboratory features.

\section{Methods}

Each infant in this report was assessed at the time that neonatal hypothyroidism was detected and was then followed up at the Hospital for Sick Children, Toronto. Two methods of screening were used. Between October 1973 and December 1978 most infants were screened using an initial thyroxine (T4) screening test on cord blood and a supplementary thyrotrophin (TSH) on the lowest $10-15 \%$ of T4 results. $^{34}$ Since January 1979 screening with an initial rapid TSH test ${ }^{15}$ from cord blood serum (recall $50 \mu \mathrm{U} / \mathrm{ml}$ ) or dried cord blood spotted on filter paper (recall $>25 \mu \mathrm{U} / \mathrm{ml}$ ) has been used. ${ }^{16} \mathrm{~A}$ few infants who had been born outside metropolitan Toronto were detected by the Ontario screening programme which uses dried heel blood collected on filter paper at between age 3 and 5 days. In these infants heel blood was assayed initially for $\mathrm{T} 4,{ }^{17}$ and a secondary TSH screening test ${ }^{16}$ was performed on the lowest $10 \%$ of the blood T4 of each assay. Any infant with a TSH value $>100 \mu \mathrm{U} / \mathrm{ml}$ on cord blood serum, or $>50 \mu \mathrm{U} / \mathrm{ml}$ on dried heel or cord blood was admitted to the Hospital for Sick Children for immediate investigation and treatment. Any infant with a TSH value of 50 to $100 \mu \mathrm{U} / \mathrm{ml}$ on cord blood serum, or 25 to $50 \mu \mathrm{U} / \mathrm{ml}$ on dried heel or cord blood was recalled for a repeat serum sample and was investigated only if repeat values showed a persistent increase in TSH for his age.

They were assessed clinically by history and complete physical examination to detect predisposing factors such as maternal diet, drug ingestion, parental consanguinity, or family history of thyroid disease or signs of hypothyroidism. At recall all infants had serum taken for repeat $\mathrm{T} 4$, triiodothyronine (T3), T3 resin uptake, and TSH. After a blood sample had been collected an $x$-ray film of the knees was taken to estimate skeletal maturation. ${ }^{18} \mathrm{~A}$ low dose radioiodine uptake using 1 to $2 \mu \mathrm{Ci}$ of ${ }^{131}$-I was obtained at 0200 and 2400 hours, and a scan employing 0.5 and $2.0 \mu \mathrm{Ci}$ of technetium-99m with doses determined on the basis of surface area was performed to define the size, location, and activity of the thyroid gland except for any infant with an obvious diffuse goitre by palpation.
Classification. Athyrosis was diagnosed if no thyroid tissue could be seen by the technetium scan. An ectopic gland was diagnosed if thyroid tissue could be seen on scanning but was in an abnormal position. The ectopic group was classified still further as lingual if the position was at the base of the tongue, or as midline ectopic if the thyroid tissue was in the neck above the normal position of the thyroid gland. Goitrous glands showed an enlarged gland on scanning with increased uptake of technetium or, if performed, an abnormal ${ }^{131}$-I uptake. Any patient in whom scanning showed a thyroid gland in a normal position with or without diminished activity was placed in the miscellaneous group that comprised infants with possible hypoplasia or borderline normal-sized glands (who were treated with thyroxine when a persistent functional abnormality was observed on follow-up recall) or infants with normalsized glands and evidence of improvement in thyroid function (transient hypothyroidism possibly due to either idiopathic ${ }^{19}$ or goitrogenic causes such as iodine $\mathrm{i}^{34}$ ).

\section{Results}

Anatomical types and incidence. Out of the 150000 infants screened in the Toronto regional cord blood screening programme, 43 with primary hypo thyroidism were detected. A further 5 infants were found in the Ontario programme, detected by heel? blood. Twelve patients were found to be athyrotic, 14 had ectopic thyroid glands, 14 had goitrous glands, and the remaining 8 comprised the miscellaneous group (Table 1). The miscellaneous group comprised 4 patients with transient hypothyroidism and 4 with hypoplasia of the gland. Some patients had scintiscans indicating normally located thyroid glands with reduced size (hypoplasia) and as they may eventually be found to have only transient hypothyroidism once they have stopped their T4 therapy we shall confine ourselves to hypothyroid infants with athyrosis, ectopic, or goitrous causes.

In the ectopic group, 11 patients were observed to have a lingual thyroid. None of these was visible clinically. Three patients were found to have a midline ectopic gland. Two of these were visible in

Table 1 Primary hypothyroidism-aetiological classification

\begin{tabular}{llcl}
\hline Types & Boys & Girls & Total \\
\hline Athyrosis & 2 & 10 & 12 \\
Ectopic & 5 & 9 & 14 \\
Goitrous & 3 & 11 & 14 \\
Hypoplasia* & 4 & 0 & 4 \\
Transient* & 1 & 3 & 4 \\
\hline
\end{tabular}

*Hypoplasia and transient causes are classified as miscellaneous. . (n) 
the neck. In the goitrous group, 9 of 10 patients who were scanned showed an enlarged gland with increased uptake of technetium. The one with a normal scan had clinical evidence of a goitre and an abnormal ${ }^{131}$-I uptake.

Clinical studies. There were more girls in all groups (Table 1), but there were no differences in the gestational ages or birthweights. There was no family history of consanguinity or thyroid disorders in any baby found to have athyrosis or an ectopic thyroid gland. A history of consanguinity was obtained from 3 families whose infants were in the goitrous group. In 2 other infants in this group there was a family history of goitre of unknown aetiology. Congenital hypothyroidism was not suspected in any patient before recall. The symptoms and signs noted at the time of recall are shown in Table 2. A goitre was noted in one baby before recall but careful examination at recall showed goitres in 12 of the 14 babies in the goitrous group.

Laboratory studies. The results of tests on T4 and TSH in the screening programme and the results of

Table 2 Symptoms and signs of hypothyroidism (at the time of recall)

\begin{tabular}{llll}
\hline & $\begin{array}{l}\text { Athyrosis } \\
(n=12)\end{array}$ & $\begin{array}{l}\text { Ectopic } \\
(n=14)\end{array}$ & $\begin{array}{l}\text { Goitrous } \\
(n=14)\end{array}$ \\
\hline Hypoactivity/lethargy & 3 & 1 & 0 \\
Poor feeding & 2 & 1 & 0 \\
Constipation & 2 & 0 & 1 \\
Icterus $>2$ days & 7 & 5 & 0 \\
Large posterior fontanelle & 3 & 1 & 0 \\
Oedema & 1 & 0 & 2 \\
Enlarged tongue & 3 & 1 & 1 \\
Hoarse cry & 0 & 0 & 0 \\
Dry skin & 3 & 0 & 0 \\
Umbilical hernia & 8 & 3 & 0 \\
Temperature $<36^{\circ} \mathrm{C}$ & 0 & 1 & 0 \\
\hline
\end{tabular}

the tests at follow-up are shown in Tables 3, 4, and 5. As can be seen there was a wide range of values for T4. The mean values \pm standard deviation were: athyrosis $4.86 \pm 1.62 \mu \mathrm{g} / 100 \mathrm{ml}(62.55 \pm 20.85$ $\mathrm{nmol} / \mathrm{l})$, ectopic $6.02 \pm 1 \cdot 74 \mu \mathrm{g} / 100 \mathrm{ml}(77 \cdot 48 \pm$ $22.39 \mathrm{nmol} / \mathrm{l})$, goitrous $5.76 \pm 1.75 \mu \mathrm{g} / 100 \mathrm{ml}$ $(74 \cdot 13 \pm 22 \cdot 52 \mathrm{nmol} / \mathrm{l})$. These differences were not significant although the athyrotic group did have a lower mean value. In all three categories of congenital hypothyroidism the centile in a particular assay in which the T4 value was located showed great variability. In the athyrosis group, Case 3 was high at the lower $7 \cdot 2$ centile of the cord run whereas all others were below the 3 rd centile. Three ectopic patients (Cases 13, 18, and 23) had values above the 3rd centile. Case 22, whose T4 was on the 27th centile, was detected fortuitously when a cord TSH was determined. In the goitrous group 4 out of the 9 infants had T4 values above the lower 3 rd centile of the $\mathrm{T} 4$ assay run.

The T4 values at recall were lower than the cord serum result in all three groups (athyrosis $2 \cdot 32 \pm$ $2 \cdot 31 \mu \mathrm{g} / 100 \mathrm{ml}(29 \cdot 86 \pm 29 \cdot 73 \mathrm{nmol} / \mathrm{l})$; ectopic $4.33 \pm 2.48 \mu \mathrm{g} / 100 \mathrm{ml}(55.73 \pm 31.92 \mathrm{nmol} / \mathrm{l})$; goitrous $3.71 \pm 3.09 \mu \mathrm{g} / 100 \mathrm{ml}(47.75 \pm 39.77$ $\mathrm{nmol} / \mathrm{l})$ ). At this time the T4 result in the athyrotic group was significantly lower than in the ectopic group $(\mathbf{P}<\mathbf{0 . 0 1})$ though not in the goitrous group. TSH values were greater than $100 \mu \mathrm{U} / \mathrm{ml}$ in every infant found to have athyrosis or an ectopic thyroid gland. Seven of the 14 patients in the goitrous group had TSH values greater than $100 \mu \mathrm{U} / \mathrm{ml}$. In 12 of these goitrous patients, the TSH value at recall was higher than it had been in the original screening test.

Skeletal maturation was delayed in 8 of 9 with athyrosis, in 6 of 11 infants with ectopy, and in 6 of 9 patients with goitres. Thus, in 7 of 30 infants with congenital hypothyroidism in whom bone age was

Table 3 Thyroid function studies-athyrosis

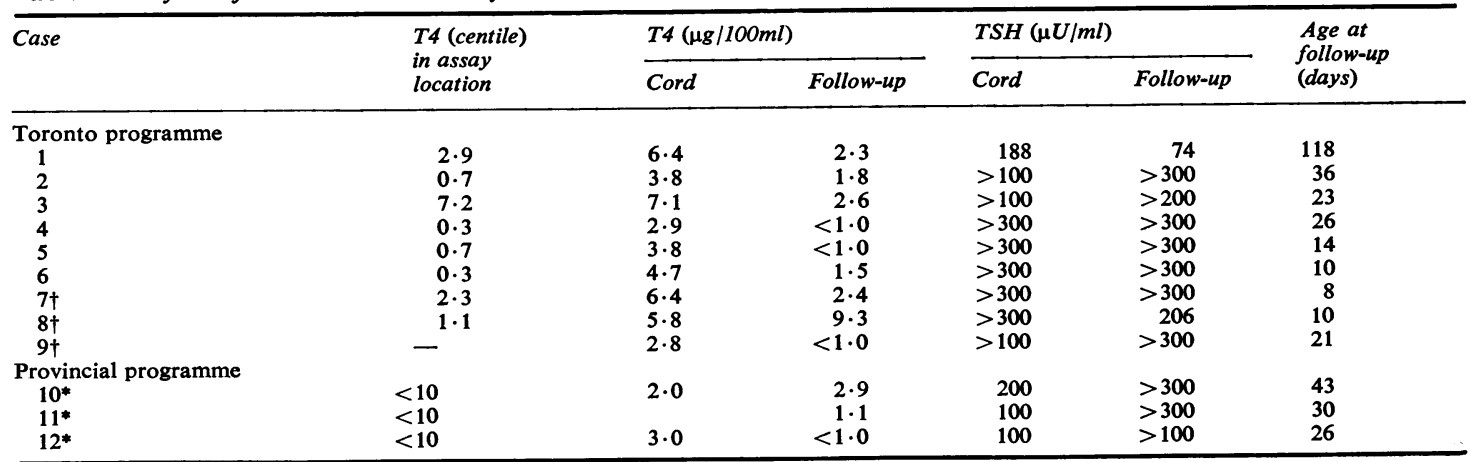

Conversion: traditional units to SI-T4 $1 \mu \mathrm{g} / 100 \mathrm{ml} \approx 12.87 \mathrm{nmol} / 1$.

*Heel blood on day 3-5. †Primary TSH. 
Table 4 Thyroid function studies-ectopic thyroid

\begin{tabular}{|c|c|c|c|c|c|c|}
\hline \multirow[t]{2}{*}{ Case } & \multirow{2}{*}{$\begin{array}{l}\text { T4 (centile) } \\
\text { in assay } \\
\text { location }\end{array}$} & \multicolumn{2}{|c|}{$T 4(\mu \mathrm{g} / 100 \mathrm{ml})$} & \multicolumn{2}{|c|}{$T S H(\mu U / m l)$} & \multirow{2}{*}{$\begin{array}{l}\text { Age at } \\
\text { follow-up } \\
\text { (days) }\end{array}$} \\
\hline & & Cord & Follow-up & Cord & Follow-up & \\
\hline \multicolumn{7}{|l|}{ Toronto programme } \\
\hline 13 & $4 \cdot 9$ & $7 \cdot 2$ & $5 \cdot 1$ & 108 & 170 & 34 \\
\hline 14 & 1.0 & $4 \cdot 7$ & $1 \cdot 5$ & $>300$ & $>600$ & 27 \\
\hline 15 & 1.4 & $3 \cdot 8$ & $<1 \cdot 0$ & $>300$ & $>300$ & 15 \\
\hline 16 & 0.6 & $4 \cdot 5$ & $2 \cdot 5$ & $>300$ & $>300$ & 14 \\
\hline 17 & $1 \cdot 6$ & $6 \cdot 5$ & $4 \cdot 8$ & $>300$ & $>300$ & 14 \\
\hline 18 & $3 \cdot 4$ & 7.9 & $6 \cdot 0$ & 172 & 153 & 23 \\
\hline 19 & $1 \cdot 0$ & $7 \cdot 6$ & $11 \cdot 0$ & 145 & 395 & 15 \\
\hline $20 t$ & 0.6 & $5 \cdot 7$ & $4 \cdot 4$ & 195 & $>\mathbf{3 0 0}$ & 9 \\
\hline $21 \dagger$ & 0.8 & $4 \cdot 8$ & $3 \cdot 5$ & $>\mathbf{3 0 0}$ & $>300$ & 14 \\
\hline $22 \dagger$ & 0.7 & $4 \cdot 7$ & $3 \cdot 3$ & $>300$ & $>300$ & 7 \\
\hline $23 t$ & $27 \cdot 7$ & 9.6 & $4 \cdot 1$ & 241 & $>300$ & 12 \\
\hline $24 \dagger$ & $1 \cdot 6$ & $5 \cdot 3$ & $6 \cdot 3$ & $>\mathbf{3 0 0}$ & 279 & 9 \\
\hline $25 t$ & - & - & $4 \cdot 7$ & $>100$ & $>200$ & 16 \\
\hline \multicolumn{7}{|l|}{ Provincial programme } \\
\hline $26 *$ & $<10$ & $5 \cdot 0$ & $2 \cdot 4$ & $>100$ & $>200$ & 16 \\
\hline
\end{tabular}

*Heel blood at day 3-5. †Primary TSH.

Table 5 Thyroid function studies-goitrous thyroid

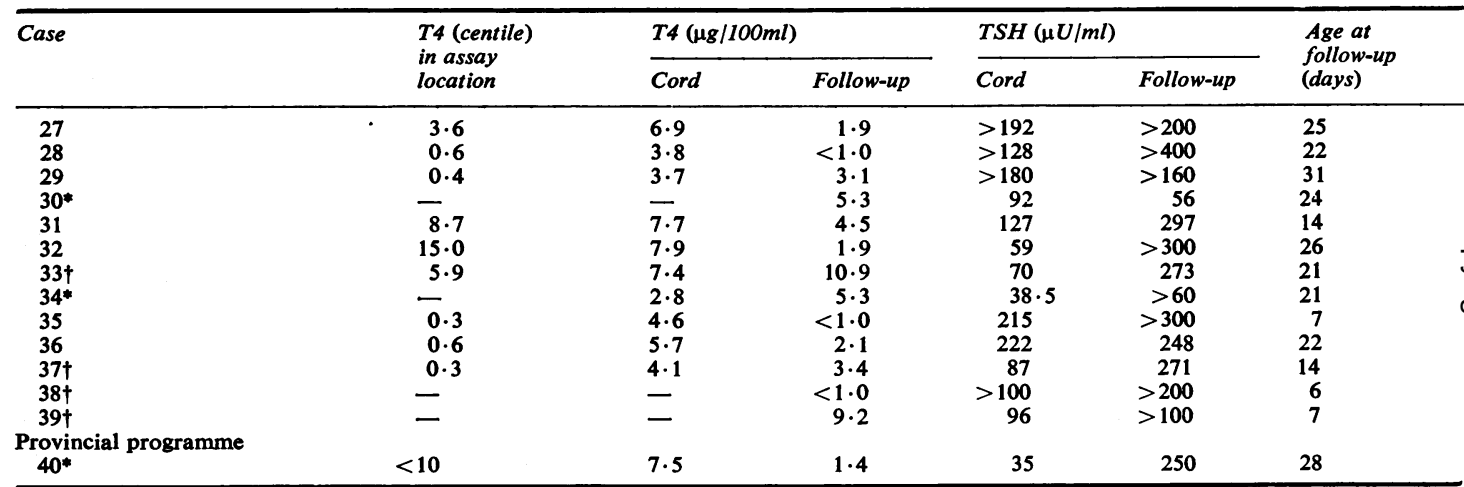

- Heel blood at day 3-5. †Primary TSH.

assessed, skeletal maturation was normal; this observation has been noted previously. ${ }^{3} 4$

The radioactive ${ }^{131}$-I uptake was significantly higher in the goitrous group at both 0200 and 2400 hours $(P<0.001$, see Table 6$)$. Although there was a difference in the mean values between the athyrotic and ectopic groups this was not significant. Eight of the athyrotic patients had normal uptakes at 0200 hours, but all were abnormally low at 2400 hours.

Table 6 Results of ${ }^{131-I}$ uptake (mean $\pm S D$ )

\begin{tabular}{lll}
\hline & 2 hours $^{*}$ & 24 hours $\dagger$ \\
\hline Athyrosis $(n=11)$ & $5 \cdot 43 \pm 3 \cdot 12$ & $1 \cdot 34 \pm 1 \cdot 06$ \\
Range & $0-8 \cdot 8$ & $0-3 \cdot 1$ \\
Ectopic $(n=12)$ & $9 \cdot 55 \pm 6.09$ & $5 \cdot 86 \pm 10 \cdot 53$ \\
Range & $4 \cdot 2-25$ & $0-38$ \\
Goitrous $(n=8)$ & $39.41 \pm 12 \cdot 15$ & $23.45 \pm 11 \cdot 18$ \\
Range & $27.9-62$ & $19 \cdot 1-40$ \\
\hline
\end{tabular}

*Normal 3-9\%. †Normal 9-26\%.
Seven of the ectopic and 9 of the goitrous group had normal values at 2400 hours. One patient with an ectopic thyroid gland had a high ${ }^{131}$-I uptake at 0200 and 2400 hours. Clinically this baby had a large midline gland and may have had an enzyme disorder as well as an ectopic gland.

Age at start of treatment. Treatment with $\mathrm{T} 4$ was started at between 6 and 120 (mean 25) days. In Case 30 it started on day 91 and in Case 1 on day 120; both these patients were found early in the screening programme but the diagnosis and treatment had to be delayed for non-technical reasons. Between October 1973 and December 1978 the age at the start of treatment for 19 infants ranged from 12 to 120 (mean 36) days. Between January 1979 and May 1980 the age at the start of treatment for 16 infants ranged from 6 to 23 (mean 14) days, which is a significant decrease $(P<0.025)$. 


\section{Discussion}

The incidence of primary hypothyroidism detected in the Toronto cord blood screening programme was 1:3488 live births. Twenty-five per cent of infants had athyrosis, $29 \%$ had ectopic glands, and $29 \%$ had goitrous glands. This is not in agreement with reports from other screening programmes. ${ }^{151314}$ There may be several reasons for this difference. The population of Toronto comprises many ethnic groups; only 3 of the 14 babies with goitres were of Anglo Saxon ancestry. Most infants were detected by using cord blood whereas other large-scale programmes have used heel blood collected at between 3 and 5 days of age. Also, we used a higher cut-off point for a secondary TSH screening test on the lowest 10-15th centile of low T4 results from cord blood ${ }^{2-4}$ as well as the lowest 10th centile for heel blood, ${ }^{17}$ unlike other centres ${ }^{20}$ which used a lower 2.5 centile of T4 results for TSH testing. ${ }^{21}$ A higher cut-off for secondary TSH testing of low T4 results is likely to detect more cases of ectopic or goitrous hypothyroidism ${ }^{21}$ since about $25 \%$ of infants with goitrous or lingual glands tend to have initial T4 results in the low to normal range. ${ }^{346}$ In many reported series, fewer than half of the patients detected were classified ${ }^{561314}$ before treatment with T4 was started and many of them may have been either ectopic or goitrous.

As in other studies we found a greater number of girls. ${ }^{3}$ The reason for this preponderance is not clear. As could be expected clinical signs were more obvious in the athyrotic group, but even so not all patients had symptoms or signs of hypothyroidism. On recall, only 9 of 40 infants were found to have more than two of the clinical criteria proposed by Smith et al..$^{22}$ to be indicative of hypothyroidism. Seven of these 9 patients were in the athyrotic group and the other two were in the ectopic group. Letarte et $a .^{23}$ designed a neonatal hypothyroid index in which various symptoms and signs were weighted according to the frequency that they found in their patients. When this index was applied to our patients only 7 of our 40 patients fulfilled their criteria, 6 of whom were in the athyrotic group and 1 was in the ectopic group. MacFaul and Grant ${ }^{24}$ summarised the frequency of symptoms and signs seen within the first month in infants presenting clinically. If their results are compared with ours (Table 2) the incidence of abnormalities in our infants is lower except for the presence of an umbilical hernia and jaundice in the athyrotic group. It is apparent therefore, that although many infants with athyrosis will be detected within the first month of life on the basis of clinical history and examination, a great many cases will be missed, especially infants with ectopic glands or goitres. In the goitrous group of patients a clinical goitre was present in most infants when they were examined by full extension of the neck.

The results of serum T4 on initial screening and follow-up showed a wide scatter, and all three groups overlapped. In several patients T4 values were normal. Fairly high initial T4 values have been reported in some athyrotic infants. ${ }^{25}$ The precise reason for this is unknown. Non-visualised functioning remnants of thyroid tissue, transient increases in thyroxine binding globulin, or maternal blood contamination are possible factors. Every patient with athyrosis or an ectopic gland had TSH values greater than $100 \mu \mathrm{U} / \mathrm{ml}$, and although several patients in the goitrous group had TSH values lower than $100 \mu \mathrm{U} / \mathrm{ml}$, each of them had a goitre present on clinical examination. From these results and from our previous reports ${ }^{2-4}$ it can be concluded that primary TSH testing is a more sensitive screening test for primary hypothyroidism. This is in agreement with the findings of other North American, ${ }^{5}$ European, ${ }^{6} 2627$ and Japanese ${ }^{9} 10$ centres.

Results of the 131-I uptakes at both 0200 and 2400 hours overlapped greatly (Table 6). Although these results were of some help in the goitrous patients they did not differentiate between patients with athyrosis and those with an ectopic gland. Furthermore, the tests delayed the start of treatment and added an extra burden of radiation to the patients. In contrast, the technetium scan was very reliable in differentiating between the three groups of patients; it gave a rapid diagnosis, thereby enabling treatment with T4 to be started even before the repeat serum T4 and TSH values became available. Only in patients in whom a thyroid scintiscan was of normal location and size was it necessary to await the repeat serum results before beginning treatment to rule out transient hypothyroidism. ${ }^{19}$ We now no longer routinely perform radioactive ${ }^{131}$-I uptakes but instead rely on a technetium scan (or preferably a ${ }^{123}$-I scan) to classify our patients.

Since January 1979 the age at which treatment began has been greatly reduced. This is partly because the screening system is now more efficient but it is also due to the use of primary TSH estimations in cord blood which was initiated in January 1979. The programme has shown the feasibility of detecting neonatal hypothyroidism from cord blood sampling. This study has also demonstrated that compared with initial T4 and supplementary TSH by either cord or heel blood screening programmes, the time between confirming the diagnosis and starting treatment can be reduced by 2 or 3 weeks if initial TSH testing is performed on cord serum or on blood spotted on filter paper. ${ }^{28}$ 
It is clear that any patient detected should be classified by scintiscanning before starting treatment in order to evaluate the long-term benefits of a neonatal screening programme for the detection of congenital hypothyroidism and to determine the mental function attained by affected infants. It will then be important to relate the underlying anatomical lesion, the severity of thyroidal hypofunction, and the time that treatment was initiated and maintained, to the mental performance achieved by infants with congenital hypothyroidism. The benefits of detection and treatment of the various types of congenital hypothyroidism discovered by neonatal screening programmes can only then be truly assessed.

We thank Mrs E Gera, Mrs M Grant, Mrs A Bansil, and $\operatorname{Dr} R$ Talosig for technical help; Mrs D Goodman for secretarial help; Mrs C Schonberg for nursing assistance; the US National Institutes of Health (National Institute of Arthritis, Digestive, and Metabolic Diseases-Pituitary Agency), the WHO, and the Division of Biological Standards, Holly Hill, UK, for supplies of TSH antisera; the Toronto chapter of the Canadian Red Cross, the obstetric and paediatric staff of all participating metropolitan Toronto hospitals, and Mrs C Bennett, Women's Auxiliary, Mount Sinai Hospital, Toronto, for voluntary help.

This work was supported by grants from Health and Welfare Canada, Ontario (Ministry of Health Project PR527 and DM467); Mount Sinai Institute and Nathan and Toby Starr Endowment Fund for Research in Mental Retardation; Department of Medicine Research Fund, Mount Sinai Hospital, Toronto; Hospital for Sick Children Foundation, Toronto (a major equipment grant).

\section{References}

1 Fisher D A, Burrow G N, Dussault J H, et al. Recommendations for screening programs for congenital hypothyroidism. J Pediatr 1976; 89: 692-4.

2 Walfish $P$ G. Evaluation of three thyroid-function screening tests for detecting neonatal hypothyroidism. Lancet 1976; i: 1208-11.

3 Walfish P G, Ginsberg J, Rosenberg R A, Howard N J. Results of a regional cord blood screening programme for detecting neonatal hypothyroidism. Arch Dis Child 1979; 54: 171-7.

4 Walfish P G, Ginsberg J, Howard N J. Results of the Toronto regionalised screening programme for detecting neonatal hypothyroidism. In: Bickel $H$, Guthrie $R$, Hammersen G, eds. Neonatal screening for inborn errors of metabolism. Berlin: Springer-Verlag, 1980: 207-17.

5 Fisher D A, Dussault J H, Foley T P, et al. Screening for congenital hypothyroidism: results of screening one million North American infants. $J$ Pediatr 1979; 94: 700-5.
6 Delange F, Beckers C, Höfer, R, König M P, Monaco F, Varrone S. Report of Newborn Committee of the European Thyroid Association. Neonatal screening for congenital hypothyroidism in Europe. Acta Endocrinol [Suppl] (Kbh) 1979; 90: Supplement 223, 5-29.

7 Walsh M P. Screening for neonatal hypothyroidism. In: An assessment of neonatal hypothyroidism screening. Proceedings of International Meeting, Peterborough, October 1978: 1-6.

8 Hulse J A, Grant D B, Clayton B E, et al. Population screening for congenital hypothyroidism. Br Med J 1980; 280: $675-8$.

9 Irie $M$, Enomoto $K$, Naruse $H$. The measurement of thyroid-stimulating hormone in dried blood spot. Lancet 1975; ii: 1233-5.

10 Miyai K, Oura T, Kawashima M, et al. A new method of paired thyrotropin assay as a screening test for neonatal hypothyroidism. J Clin Endocrinol Metab 1978; 47: 1028-33.

11 Wilkins L. Hypothyroidism in children. In: Astwood E B, ed. Clinical endocrinology. Vol. 1. New York: Grune \& Stratton, 1960: 112-22.

12 Carr E A, Beierwaltes W H, Neel J V, et al. The various types of thyroid malfunction in cretinism and their relative frequency. Pediatrics $1961 ; 28: 1-6$.

13 Mitchell M L, Larsen P R, Levy H L, Bennett A J E, Madoff M. Screening for congenital hypothyroidism. Results in the newborn population of New England. JAMA 1978; 239: 2348-52.

14 LaFranchi S H, Murphey W H, Foley T P, Jr, Larsen P R, Buist N R M. Neonatal hypothyroidism detected by the northwest regional screening program. Pediatric 1979; 63: 180-91.

15 Rosenberg R A, Gera E, Walfish P G. A rapid double antibody non-equilibrium serum thyrotropin radió immunoassay suitable for primary neonatal hypothy. roidism screening. Clin Chim Acta 1979; 92: 209-19.

16 Walfish P G, Gera E. Experience with the application of a dried blood thyrotropin (TSH) method for neonatal hypothyroidism screening: comparative studies between double-antibody and solid phase radioimmunoassays. In: Bickel H, Guthrie R, Hammersen G, eds. Neonatal screening for inborn errors of metabolism. Berlin: SpringerVerlag, 1980: 219-28.

17 Walfish P G, Gera E, Wood M M. Methodologic limitations on the measurement of thyroxine from small dried blood discs: comparison of double-antibody and solid phase radioimmunoassays. In: Bickle $H$, Guthrie $R$, Hammersen G, eds. Neonatal screening for inborn errors of metabolism. Berlin: Springer-Verlag, 1980: 229-39.

18 Greulich W W, Pyle S I. Radiographic atlas of skeletal development of hand and wrist, second edition. Stanford: Stanford University Press, 1959.

19 LaFranchi S H, Buist N R M, Murphey W H, Larsen P R, 옹 Foley T P, Jr. Transient neonatal hypothyroidism detected by newborn screening program. Pediatrics 1977; 60: 538-41.

20 Morissette J, Dussault J H. Commentary: The cut-off $N$ point for TSH measurement or recalls in a screening program for congenital hypothyroidism using primary T4 screening. J Pediatr 1979; 95: 404-6.

21 Walfish P G, Wood M M. Letter: Cut-off for supplementary TSH testing in a T4 screening program for congenital hypothyroidism. J Pediatr 1981; 99: 164-5.

22 Smith D W, Klein A M, Henderson J R, Myrianthopoulos $\mathrm{N}$ C. Congenital hypothyroidism-signs and $\mathbb{D}$ symptoms in the newborn period. $J$ Pediatr 1975; 87: 958-62. 
23 Letarte J, Guyda H, Dussault J H. Clinical, biochemical, and radiological features of neonatal hypothyroid infants. In: Burrow G N, Dussault J H, eds. Neonatal thyroid screening. New York: Raven Press, 1980: 225-35.

24 MacFaul R, Grant D B. Early detection of congenital hypothyroidism. Arch Dis Child 1977; 52: 87-8.

25 Klein A H, Foley T P, Jr, Larsen P R, Agustin A V, Hopwood N J. Neonatal thyroid function in congenital hypothyroidism. J Pediatr 1976; 89: 545-9.

26 Illig R, Torresani T, Sobradillo, R. Early detection of neonatal hypothyroidism by serial TSH determination in dried blood. Helv Paediatr Acta 1977; 32: 289-97.

27 Hulse J A, Jackson D, Grant D B, Byfield P G H, Hoffenberg R. Different measurements of thyroid function in hypothyroid infants diagnosed by screening. Acta Paediatr Scand [Suppl] 1979; 277: Supplement, 21-5.
28 Howard N J, Thores O A, Walfish P G. Screening for neonatal hypothyroidism: a comparison between cord blood screening and neonatal filter paper heel blood programs in Ontario (abstract 77). In proceedings of the Sixty-Second Annual Meeting of the Endocrine Society, Washington DC, June 1980: 94.

Correspondence to Dr Paul G Walfish, Mount Sinai Hospital, Suite 639-40, 600 University Avenue, Toronto, Ontario M5G 1X5, Canada.

Received 4 August 1980 